\title{
Sensitivity of the global submarine hydrate inventory to scenarios of future climate change
}

\author{
S.J. Hunter ${ }^{\mathrm{a}, *}$, D.S. Goldobin ${ }^{\mathrm{b}, \mathrm{c}}$, A.M. Haywood ${ }^{\mathrm{a}}$, A. Ridgwell ${ }^{\mathrm{d}}$, J.G. Rees ${ }^{\mathrm{e}}$ \\ ${ }^{a}$ School of Earth and Environment, University of Leeds, UK \\ ${ }^{b}$ Department of Mathematics, University of Leicester, UK \\ ${ }^{c}$ Institute of Continuous Media Mechanics, UB RAS, Perm, Russia \\ ${ }^{d}$ School of Geographical Sciences, University of Bristol, UK \\ ${ }^{e}$ British Geological Survey, UK
}

\section{Abstract}

10 The global submarine inventory of methane hydrate is thought to be considerable. The 1 stability of marine hydrates is sensitive to changes in temperature and pressure and once 12 destabilised, hydrates release methane into sediments and ocean and potentially into the ${ }_{13}$ atmosphere, creating a positive feedback with climate change. Here we present results 14 from a multi-model study investigating how the methane hydrate inventory dynamically responds to different scenarios of future climate and sea level change. The results indicate that a warming-induced reduction is dominant even when assuming rather extreme rates of sea level rise (up to $20 \mathrm{~mm} \mathrm{yr}^{-1}$ ) under moderate warming scenarios (RCP 4.5). Over the next century modelled hydrate dissociation is focussed in the top $\sim 100 \mathrm{~m}$ of Arctic and Subarctic sediments beneath $<500 \mathrm{~m}$ water depth. Predicted dissociation rates are particularly sensitive to the modelled vertical hydrate distribution within sediments. Under the worst case business-as-usual scenario (RCP 8.5), upper estimates of resulting global sea-floor methane fluxes could exceed estimates of natural global fluxes by 2100 (> 30-50 $\mathrm{Tg} \mathrm{CH}_{4} \mathrm{yr}^{-1}$ ), although subsequent oxidation in the water column could reduce peak atmospheric release rates to 0.75 to $1.4 \mathrm{Tg} \mathrm{CH}_{4} \mathrm{yr}^{-1}$. Keywords: methane hydrate; anthropogenic; climate change

\section{Introduction}

Hydrates are crystalline cage structures which enclose low molecular-weight gases, primarily methane. The most common type, stratigraphic deposits, form over geological timescales within sediment pore space when methane and water are in close proximity in high-pressure low-temperature environments typical of continental shelf margins. Many studies have estimated the size of the global inventory. Early work (reviewed in Milkov (2004) ) estimated the inventory to be of the order of 10,000 GtC (i.e. Kvenvolden (1999) ) which was subsequently refined to between 500 - 3000 GtC (Buffett and Archer,

${ }^{*}$ Corresponding author. School of Earth and Environment, University of Leeds, Leeds, LS2 9JT, UK. Tel.: +44 1133439085; Fax: +44 1133435259 . 
2004, Archer, 2007, Wallmann et al., 2011, Piñero et al., 2012) although lower estimates exist (i.e. $50 \mathrm{GtC}$ Burwicz et al. (2011) assuming only microbial $\mathrm{CH}_{4}$ sources) as well as optimistically large outliers (e.g 74,000 GtC Klauda and Sandler (2005)). Boswell and Collett (2010) concluded this lack of clear convergence was due to poor data-availability and uncertainty in initial model assumptions.

Regardless, the dependence of methane hydrate stability on temperature and pressure and their existence around continental shelf margins mean that they are sensitive to changes in bottom water conditions and sea-level. However, while methane hydrates would likely provide a positive feedback to climate warming, the strength of this feedback is modulated by concurrent rises in sea-level, which would provide a stabilizing influence by increasing local hydrostatic pressure. How these two opposing influences combine has not previously been assessed in a temporal and quantitative manner, nor has the uncertainty in hydrate destabilization imparted by different emissions forcing scenarios. Defining future climate scenarios from an evaluated multi-climate-model ensemble ensures that our hydrate model boundary conditions are robust and not determined by biases in a single model.

\section{Methods}

We use climate model experiments from the CMIP5 multi-model ensemble, evaluated against modern observations to define a series of future anthropogenic-warming climatic scenarios. Modelling the propagation of bottom water temperature change $(\triangle \mathrm{BWT})$ through the continental margin sediment column in combination with a series of linear sea level models allows a series of time-profiles of the change in the hydrate stability zone volume to be calculated. Using a hydrate model to derive an initial pre-industrial global hydrate inventory we then compute its evolution and derive rates of hydrate dissociation. This procedure allows the first-order response of the hydrate inventory to be determined through and beyond a series of anthropogenic warming scenarios.

\subsection{CMIP5}

The World Climate Research Programme (WCRP) Fifth Coupled Model Intercomparison Project (CMIP5) is a globally coordinated model-intercomparison setup to address questions raised within IPCC AR4 (Taylor et al., 2011). We conduct hydrate modelling under boundary conditions derived from a subset of the CMIP5 long-term experiments namely the pre-industrial (CMIP5 Experiment 3.1), historical (Exp 3.2) and the RCP and ECP future responses ( $\operatorname{Exp} 4.1$ - 4.4, 4.1L - 4.3L), covering the climate from 1860 to 2300 .

\subsubsection{Pre-industrial and historic climate model experiments}

The pre-industrial climate experiments (pre-1860; piControl) have been run with fixed atmospheric composition and unperturbed land use. The historic experiment (18602005) has changing atmospheric composition (anthropogenic and natural), solar forcings and land use change according to historical records. Details of boundary conditions are summarised within Taylor et al. (2011), WCRP (2012). The pre-industrial experiments are used to determine climatic drift and to initialise the global hydrate inventory. The historical experiments are used in the evaluation of models against observations and to initialise climatic scenarios. 


\subsubsection{RCP scenarios}

Representative Concentration Pathways (RCP, Moss et al. (2010) ) describe possible climate scenarios of future greenhouse gas emissions for the period $2005-2100$. The RCPs are labeled according to their approximate global radiative forcing at $\sim 2100$. They represent the range of published emission scenarios as of 2007. They have been extended to 2300 leading to Extended Concentration Pathways (ECP, Meinshausen et al. (2011) ). A summary of these scenarios can be found within Table 1 and details of those modelled in Table 3 .

\subsubsection{Climate models}

Twelve climate models were available within the CMIP5 database (as of Jan 2012) that had carried out pre-industrial, historical and at least one RCP scenario, these are detailed within Tables 2 and 3. These consist of Atmosphere-Ocean General Circulation Models (AOGCM) and Earth System Models (ESM), the latter incorporating additional earth system components such as biogeochemical cycles and atmospheric chemistry. Common to all models is an ocean general circulation model which we use to define bottom water conditions - the uppermost boundary condition of our hydrate model.

Native model grids were translated onto a $2 \times 2^{\circ}$ geographic grid using a model specific weight-matrix derived from an inverse-distance weighting of nearest-neighbors, a method based upon Jones (2001). Potential temperature and salinity fields were extracted from the bottom-most layer of the 3D data. Conversion to in-situ temperature was achieved using the solution of Jackett et al. (2006) which uses bottom water pressure (BWP) and salinity to uncouple potential and in-situ temperature. When modelled-BWP was unavailable the bathymetry $(D)$ and constant mean density $\left(\rho_{0}=1035 \mathrm{~kg} \mathrm{~m}^{-3}\right)$ was used to estimate BWP assuming $P=\rho_{0} g D$. Using climate models with modelled BWP it was found that the bathymetric approximation was $\sim 0-0.5{ }^{\circ} \mathrm{C}$ warmer than the true in-situ temperature. Despite this error, the conversion of potential temperature to in-situ temperature is important as without conversion, potential temperatures can be $>0.75$ ${ }^{\circ} \mathrm{C}$ warmer than in-situ. The use of the bathymetric approximation therefore provides a solution which is closer to the true in-situ temperature than potential temperature. We consider this justifiable as we find no correlation between model performance and the use of either bottom water pressure or the bathymetric approximation.

\subsection{Computational Domain}

We restrict calculation to the marine sediment of continental margins as defined by Buffett and Archer (2004) (Figure 1). Whilst other methods that constrain geographic distribution were considered such as organic carbon supply (Gornitz and Fung, 1994, Harvey and Huang, 1995) and coastline distance (Fyke and Weaver, 2006), these have weaknesses (discussed within Archer (2007) ) and results would have proven difficult to interpret and evaluate. Whilst the mask restricts maximum geographical extent, water depth and bottom water temperature act to impose on hydrate distribution within the mask. Bathymetry is from ETOPO2v2 (U.S. Department of Commerce, 2006) and resampled to $2 \times 2^{\circ}$ using area-weighted regridding. We assume that for each model, the regridded $2 \times 2^{\circ}$ in-situ $\mathrm{BWT}$ is equivalent to this regridded bathymetry. 


\subsection{Climate model evaluation and model-weighting scheme}

It is desirable to have an initial pre-industrial bottom water state which is in equilibrium as this ensures subsequent bottom water warming (i.e. during historic and $\mathrm{RCP} / \mathrm{ECP}$ experiments) is in response to changes in boundary conditions rather than inadequate model spin-up. Given long ventilation timescales of the deep ocean, sufficiently long model integrations are generally not available with current generation climate models. Fortunately the design of CMIP5 experiments allows potential model drift to be corrected. The historic experiment is initialised from a branch-point within the preindustrial experiment. The pre-industrial experiment then continues until it extends to the end of the combined historic ( 1850-2005) and future runs (2005-2100/2300). Underlying climatic drift within modelled pre-industrial bottom waters can then be $s u b$ tracted from the historic and RCP/ECP experiments. Once the underlying model drift is removed the in-situ BWT is then used as the upper boundary condition for the hydrate modelling (globally integrated BWT shown within Supplementary Figure 1). Unfortunately the BCC-CSM climate model results had to be omitted from the analysis as the pre-industrial experiment was of insufficient length to correct historic and future scenario model runs.

To determine the prediction capability of each climate model, the modelled historic BWT is evaluated against the World Ocean Atlas 2005 objectively-analyzed data-set (WOA05; Locarnini et al. (2006) ). For each model, we first derive the mean in-situ BWT for the WOA05 observational period (1954-2005). We then filter WOA05 data to sites that have $\geq 50$ separate observations and conduct point-wise comparisons over the entire ocean and margins (Supplementary Figure 2). We calculate the $\mathrm{r}^{2}$ statistic over the margin $\left(\mathrm{R}_{m}^{2}\right)$ and whole ocean $\left(\mathrm{R}_{o}^{2}\right)$.

In addition we derive the Arcsin Mielke score (AMS, Watterson (1996) ) between model and data over the whole ocean. This non-dimensional metric measures how two geographic fields compare in terms of magnitude and spatial patterns. For each model we then derive performance weights from the product of $\left(R_{m}^{2} \cdot R_{o}^{2}\right)^{1 / 2}$ and AMS, shown within Table 2 . These performance weights are then used to generate multi-model means of bottom water temperatures through the historic and future scenarios.

\subsection{Sea level models}

There is considerable uncertainty associated with developing models of sea-level over millennial timescales due to underlying sensitivities (i.e. changing orbit), uncertain longterm climate trajectory, non-linear climate ice-sheet interactions, complex ice-sheet dynamics, and poorly assessed isostatic adjustments. We therefore consider a range of linear sea-level change models from 1 to $20 \mathrm{~mm} \mathrm{yr}^{-1}$ until the complete depletion of the Western Antarctic and Greenland Ice-sheets has been attained. Whilst arbitrary, the models provide means to assess the sensitivity of the hydrate inventory to potential anthropogenic sea-level change under a range of warming scenarios. This envelope encapsulates a range of AR4 SRES-based sea-level projections of between $0.5-1.9 \mathrm{~m}$ by 2100 ( $\sim 5$ to $19 \mathrm{~mm} \mathrm{yr}^{-1}$, e.g. Rahmstorf (2007), Vermeer and Rahmstorf (2009), Jevrejeva et al. (2010) ) which incorporate thermal expansion estimated to be $0.1-0.4 \mathrm{~m}$ by 2100 (Solomon et al., 2007). Whilst extrapolation beyond 2100 is unsupported by projections we do this to cover the thermal propagation timescale within sediments (multi-century to millennial). 
For consistency these models are applied to each RCP/ECP scenario irrespective of its design. Our models do not incorporate thermal expansion or large-scale mass redistribution as these drive no significant BWP change. As we are primarily interested in present to 2100 or 2300 timescales, we do not consider any changes in land-sea mask, sedimentation regimes, isostatic effects or the formation of new areas within which hydrates will be stable.

\subsection{Computing global Hydrate Stability Zone volume}

For each scenario (piControl-historic-RCP/ECP) we propagate $\triangle \mathrm{BWT}$ through the sediment column of each $2 \times 2^{\circ}$ cell within the continental margin (Figure 1). Initial down-column temperatures are assumed to be in steady-state (i.e. linear) such that the local geothermal gradient, $G_{x y}$, is defined by Equation 1, where suffix $x y$ indicates a geographic field.

$$
G_{x y}=-\frac{f_{x y}}{\kappa}
$$

With $f_{x y}$ the seafloor heat flux, we assume an average sediment thermal conductivity, $\kappa$, of $1.5 \mathrm{Wm}^{-1} \mathrm{~K}^{-1}$ (Burwicz et al., 2011). Despite hydrate having a thermal conductivity of between 0.5 and $2.1 \mathrm{Wm}^{-1} \mathrm{~K}^{-1}$ (Golmshtok and Soloviev, 2006) we assume that hydrate within sediment pore space does not modify the bulk thermal conductivity as it is disseminated in relatively low fraction (typically $<5 \%$ ). For $f_{x y}$ we use the heat flux reconstruction of Hamza et al. (2008), an extrapolation of reanalysed International Heat Flow Commission data (Pollack et al., 1993).

Once the local geothermal gradient is derived, down-column temperatures are calculated assuming an upper boundary specified by the pre-industrial in-situ BWT. Changes in BWT are then transported through the sediment column using the thermal propagation model described by Equation 2.

$$
T(z, t)=\int_{0}^{\infty} \frac{T_{o}(z=0, t-\tau)}{\sqrt{2 \pi \chi}} \frac{z^{2}}{2 \chi \tau} \exp \left[-\frac{z^{2}}{2 \chi \tau}\right] d \tau+G z
$$

Where $\tau$ is the integration parameter, $T(z=0, t)$ is the seafloor temperature at time $t$, and $z$ is the depth below the seafloor. We assume a constant thermal diffusivity, $\chi$ of $5 \times 10^{-7} \mathrm{~m}^{2} \mathrm{~s}^{-1}$ (Fyke and Weaver, 2006) and an initial geothermal gradient, $G$, derived from Equation 1. We solve Equation 2 for each grid cell using a 10 year time step and forward model to year 2850. As we move beyond the RCP/ECP time frame (beyond 2100 or 2300) bottom water conditions are held fixed at the last decade of the scenario. Predictions beyond the scenario therefore represent the future response built into the subsea system (i.e. what's-in-store) given these final conditions. Pressure differences arising from sea-level change (Section 2.4) are assumed to propagate the sediment column instantaneously.

For each time step we compute the top (THSZ) and bottom (BHSZ) of the hydrate stability zone (HSZ) (Figure 2). Given a down-column temperature profile specified at discrete depth bins we first compute the pressure at each depth, equivalent to the overlying water and sediment using the following equation:

$$
P(z)=(D+z) \times \rho g
$$


Where $D$ is water depth $(\mathrm{m}), z$ the thickness of overlying sediment $(\mathrm{m}), \rho$ is the sea water density $\left(1035 \mathrm{~kg} \mathrm{~m}^{-3}\right)$ and $g$ is the acceleration due to gravity $\left(9.81 \mathrm{~m} \mathrm{~s}^{-2}\right)$. We assume pore fluid pressure is hydrostatic and neglect any potential pressure change due to dissociation processes.

For each depth cell we compute the corresponding three-phase temperature $\mathrm{T}_{3}$, by extrapolation of $\mathrm{T}_{3}(\mathrm{P})$ hydrate stability data derived from the empirical solution of Tishchenko et al. (2005) for pure methane hydrate (Type-I) and pore water salinity of 35 $\%$. When $\mathrm{T}_{3}$ has been computed for all depth cells we find the depths in which $T(z)-T_{3}$ is minimized, taking care to discriminate between the base (BHSZ) and if present within the sediment column, the upper boundary (THSZ). We conduct this calculation for each cell column within the continental margin (Figure 1) for each time-step and derive the global volume (gHSZv) from the products of HSZ thickness and lateral cell area. This procedure is repeated for each sea level model (e.g. $5 \mathrm{~mm} \mathrm{yr}^{-1}$ ) for each modelled scenario (e.g. RCP 4.5) done by each model (e.g. CanESM2).

The Sulphate Reduction Zone (SRZ, Figure 2) extends from the seafloor to a depth in which the sulphate concentration is negligible. Within the SRZ, sulphate and methane are consumed primarily by anaerobic oxidation of methane (AOM). We assume a globallyfixed none-dynamic SRZ of $10 \mathrm{~m}$ depth. Whilst SRZ-thickness varies greatly, i.e. $\sim 10$ - $200 \mathrm{~m}$ (Claypool and Kvenvolden, 1983, Borowski et al., 1999, D'Hondt et al., 2002) data is insufficient to allow reliable modelling of SRZ distributions. This omission may lead to over-prediction of near-term shallow hydrate dissociation.

Given significant computational requirements we make the following approximations when modelling HSZ extent. We neglect latent heat and so assume that temperature change due to the endothermic hydrate dissociation process is not imparted on the geothermal gradient. We therefore expect to over-predict slightly the speed at which the HSZ shrinks. Similarly pore water freshening following hydrate dissociation is not represented and so does not act to suppress further shrinkage. In doing so we neglect resulting changes in three-phase equilibria and methane solubility.

\subsection{Modelling global hydrate volume and rates of dissociation}

We use the sediment porosity model described within Davis et al. (1990) which assumes that porosity, $\delta(z)$ decreases exponentially with depth (Equation 4). A surface porosity of $\delta(0)$ of 0.65 and an e-folding depth, $L$ of $1500 \mathrm{~m}$ are used throughout.

$$
\delta(z)=\delta(0) \exp \left(\frac{-z}{L}\right)
$$

We define two hydrate models. The first assumes that sediment pore space is uniformly filled with a constant hydrate fill fraction of 0.01 , a method similar to early global HSZ estimations (MacDonald, 1990, Milkov et al., 2003). Results from this model can then be linearly scaled given a global mean hydrate fill fraction.

The second uses a 1D time-dependent hydrate model (the model of Davie and Buffett (2001) and Davie (2002) converted to Fortran 90) to specify how the HSZ is initially filled. For each model we derive a pre-industrial inventory using fixed boundary conditions over the continental margins (Figure 1). Average bottom water temperatures are derived from the final 50 years of the pre-industrial experiment (piControl). We assume a steady-state geothermal gradient and define HSZ extent using a method which is internally consistent with Section 2.5. Sediment rates and carbon rain are derived following the method of 
Buffett and Archer (2004) using a parameterisation based ultimately upon water depth (Middelburg et al., 1997). Muds sedimentary diagenesis model output (Archer et al., 2002, Buffett and Archer, 2004) and the modern record of dissolved oxygen concentration (WOA05, Garcia et al. (2006) ) are used to compute buried carbon fraction. Table 4 details geographically invariant variables used within the modelling.

Our calculations differ from Buffett and Archer (2004) in several ways. We determine local geothermal gradients from a global heat flux data-set and average sediment heat conductivity. Our calculation of the HSZ vertical extent is sensitive to top-down changes in the HSZ. We do not explicitly distinguish between active and passive margins (Davie and Buffett, 2003, Buffett and Archer, 2004), as upward fluid advection is highly localised and so not possible to parameterize to global domains. Finally we use the empirical solution of Tishchenko et al. (2005) to define hydrate stability which is more robust and provides an improved fit to observations.

In building an initial hydrate inventory using pre-industrial boundary conditions we neglect changes in sea level, BWT, sediment supply and isostatic adjustments. The hydrate model is run for 10 Myr to reach a state of three-phase equilibrium.

The geographic fields of the initial down-column hydrate concentrations are then integrated with the time-series of HSZ change (Section 2.1.2) to derive the temporal evolution of hydrate dissociation. We assume only BWT and sea-level driven changes to THSZ and BHSZ drive hydrate dissociation and so neglect hydrate dissociation following solubility changes that arise from local changes in pressure, temperature and salinity. We assume that during the modelling time-frame hydrate formation is negligible.

We repeat this procedure for each model in the scenario and form a Multi-Model Mean using normalised-weights. Given that the ECP scenario contains a reduced model subset to the corresponding RCP scenario the two are discontinuous in terms of model mean climate and hydrate inventory. We attempt to rationalise this by presenting changes in global volume in terms of fractional change relative to the initial pre-industrial state.

\section{Results}

For brevity all the following results are multi-model means (i.e. the weighted mean of multiple climate models that represent each $\mathrm{RCP} / \mathrm{ECP}$ scenario). Climate model descriptions and performance weights are found in Table 2, their contribution to each RCP scenario are detailed within Table 3. Figures detailing results of sea level models are found within the supplementary section.

\subsection{Evolution of the global HSZ volume (gHSZ)}

The initial pre-industrial global HSZ volume $(\mathrm{gHSZv})$ is $1.77 \times 10^{7} \mathrm{~km}^{3}$ (multi-model range is $1.66-1.89 \times 10^{7} \mathrm{~km}^{3}$ ). Assuming an average porosity of $50 \%$ we obtain a mean global occupiable space of $8.9 \times 10^{6} \mathrm{~km}^{3}$ which compares favorably with previous estimates of $3.5-16 \times 10^{6} \mathrm{~km}^{3}$ (MacDonald, 1990, Gornitz and Fung, 1994, Harvey and Huang, 1995, Dickens, 2001).

The evolution of gHSZv during and following RCP and ECP scenarios is shown within Figure 3. At 2100 pre-industrial gHSZv has shrunk by $0.032 \%$ (RCP 4.5) to 0.040 $0.044 \%$ (RCP/ECP 8.5 the business-as usual scenario) and by 2300 pre-industrial gHSZv has shrunk by $0.15-0.68 \%$. At 2300 ECP 8.5 has $3 \times$ the impact of ECP 4.5 in terms 
of gHSZv reduction (ECP 6.0 not available, Table 3). Continuation of ECP 8.5 model runs beyond 2300 would significantly enhance gHSZv reduction. Over the next millennium ECP 4.5 has similar impact to RCP 8.5, although the latter will have significant unrepresented residual heat propagating the water column through $2100-2300$.

Incorporating changes in sea level (Supplementary Fig. 3) counteracts some gHSZv reduction although no sea-level model comes close to fully over-riding the thermal impact of any the RCP scenarios. As we artificially stabilize sea level at $+12 \mathrm{~m}$ heat-induced shrinking over-rides sea level and results converge, for 20 and $15 \mathrm{~mm} \mathrm{yr}^{-1}$ this occurs at $\sim 2450$ and 2650 respectively.

If we were to consider the expansion of gHSZv beyond the initial pre-industrial state (i.e. fraction $>1$ ) then sea-level would appear to compensate the effects of warming over the scenario duration (to 2100 or 2300 ) for $\geq 10 \mathrm{~mm} \mathrm{yr}^{-1}$ (RCP 4.5 - 6.0) and $\geq 15 \mathrm{~mm} \mathrm{yr}^{-1}$ (RCP 8.5 and ECP 4.5). However, this expansion beyond pre-industrial reflects the immediate deepening of the BHSZ and so compensates (within the gHSZv calculation) any top-down HSZ reduction within which we are interested. One therefore must be careful in specifying gHSZv when considering both sea-level and temperature change, as deepening of the BHSZ beyond the initial pre-industrial state does not affect the exogenic carbon cycle. Hence we defined the reported gHSZv as the reduction from the initial pre-industrial state, although expansion beyond the initial pre-industrial state is modelled (as it may later contract).

Figure 4 shows the global evolution of RCP/ECP 8.5 HSZ reduction in relation to overlying water and sediment depth where HSZ is reduced. Differences in historical response (1860 - 2005) between scenarios are due to different model subsets. As expected we see a minima in overlying water depth $(\sim 240 \mathrm{~m})$ corresponding to cold Arctic waters (intra- and sub-permafrost hosted hydrates were not modelled), and in sediment depth $(10 \mathrm{~m})$ corresponding to the prescribed SRZ thickness. It is likely that the earliest indication of HSZ reduction during the historical period (Figure 4) has a contribution from regional climate model disequilibrium. Nevertheless, this does not exclude the possibility of top-down HSZ reduction during warming of the historical period, although this is currently difficult to quantify.

The time profile of the deepest sediment influenced depends upon the propagation speed of the thermal signal described by Equation 2. The profile (dotted line within Figure $4(\mathrm{e})$ ) originates between $\sim 1950$ and 2000 and propagates $\sim 150 \mathrm{~m}$ within $\sim 350$ years. This is greater than the $180 \mathrm{~m}$ within 1000 years suggested by Archer (2007) which could reflect the choice in thermal diffusivity, $\chi$, or a background component from pre-industrial disequilibrium. Differences in RCP and corresponding ECP scenario prior to 2100 are due to differences in model subsets (Table 3).

The latitudinal distribution of HSZ reduction partitioned by overlying water depth is shown within Figure 5. We find HSZ reduction focussed within the Arctic and Subarctic. Prior to 2100 the lower-latitudes contribute little but this intensifies over the next two centuries as the deeper waters respond to atmospheric warming and subsequent $\triangle \mathrm{BWT}$ propagate the sediment column. Comparing Figure 4(e) with Figure 5 allows the separation of Arctic and deeper lower-latitude waters. The precise reason for the shallow and deep water grouping $(<\sim 500 \mathrm{~m}>)$ within Figure $4(\mathrm{e})$ is uncertain, but could result from the depth and geographic-distribution of sensitive bottom waters or the propagated signal of unequilibriated BWTs. As overlying water and sediment depth will ultimately modulate how much methane from dissociated hydrate can reach the atmosphere it is 
clear that the high-latitude shallow deposits will present the largest potential atmospheric forcing.

\subsection{Hydrate evolution}

Whilst the purpose of this study is not to generate an improved estimate of the global hydrate inventory (our methods do not provide mechanistic improvements over existing estimates) it is reassuring that the multi-model mean pre-industrial state leads to an inventory of $3830 \mathrm{GtC}$, comparable to, if slightly higher than, the widely considered range of 500 - $3000 \mathrm{GtC}$. Of this $405 \mathrm{GtC}(11 \%)$ is held within the Arctic $(>60 \mathrm{~N})$ a value similar to previous estimates (Kvenvolden, 1988b). It should be noted that this estimate does not include subsea permafrost-associated hydrates which were omitted due to computational constraints. The global average hydrate saturation is $1.2 \%$ with latitudinal averages ranging from 0.7 and $2.3 \%$.

We first consider time-dependent results from the simplistic model where methane hydrate uniformly occupies a fixed fraction of pore-space. Results for an average $1 \%$ fill are shown within Figure 6. We find that dissociation begins within the historical period ( 1950 - 2000) and increases significantly at $\sim 2000$ (RCP onset) until the close of the RCP/ECP scenario. Global mean dissociation rates for different scenarios from 2000 to $\sim 2050$ are indistinguishable. For $1 \%$ pore-fill fraction, RCP 4.5 has a mean of $\sim 39 \mathrm{Tg} \mathrm{CH}_{4} \mathrm{yr}^{-1}$ (model spread of the mean is $47 \pm 25 \mathrm{Tg} \mathrm{CH}_{4} \mathrm{yr}^{-1}$ ) and a peak rate of $\sim 111 \mathrm{Tg} \mathrm{CH}_{4} \mathrm{yr}^{-1}$, for RCP 6.0 these are $40(63 \pm 33)$ and $110 \mathrm{Tg} \mathrm{CH}_{4} \mathrm{yr}^{-1}$, and RCP $8.549(55 \pm 26)$ and $152 \mathrm{Tg} \mathrm{CH}_{4} \mathrm{yr}^{-1}$. This lack of difference arises due to the propagation timescale of atmospheric warming to bottom waters, the different sensitivities of ocean models in each RCP subset then act to blur/average this initial response. Beyond $\sim 2050$ dissociation rates diverge as expected. Maximum peak rates occur slightly after 2100 with values of 121,192 and $205 \mathrm{Tg} \mathrm{CH}_{4} \mathrm{yr}^{-1}$ for RCP 4.5, 6.0 and 8.5. At $\sim 2300$ ECP 4.5 and 8.5 have peak dissociation rates of $\sim 205$ and $\sim 760 \mathrm{Tg}$ $\mathrm{CH}_{4} \mathrm{yr}^{-1}$. Given model assumptions, dissociation rates scale linearly with global-mean hydrate pore fill-fraction. Globally this is expected to lie within $\sim 1-3 \%$ pore-fraction (reviewed within Milkov (2004)). Comparing Figure 6 against Figures 4 and 5 shows that most of this dissociation will occur in the top $\sim 150 \mathrm{~m}$ of Arctic and Subarctic sediment, arising primarily from top-down dissociation.

Peak dissociation rates are relatively insensitive to modelled rates of sea-level change (Figure 6). Between 2000 and 2100 it is difficult to distinguish sea-level effects above statistical noise. Beyond 2100 sea-level change leads to distinguishable differences in dissociation rate. This is expected given the onset of significant change in gHSZv (Section 3.1 and Supplementary Fig. 3).

Figure 7 shows time-dependent results derived from the 1D hydrate model derived global inventory (Section 2.6 and Table 4). Dissociation rates are significantly reduced compared to the previous $1 \%$ hydrate fill fraction experiment, despite a global inventory which is similar to current best-estimates and the $1 \%$ fill experiment. Investigating the vertical distribution of modelled hydrate indicates this discrepancy is due to the shallowest hydrate lying at $\sim 110 \mathrm{~m}$ - significantly deeper than the base of the SRZ where the shallowest hydrate lie within the fixed-fill fraction model. This vertical distribution is also demonstrated within Buffett and Archer (2004, Fig. 5); this is expected as our model is derived from the same hydrate model (Davie and Buffett, 2001). Modelled dissociation is likely due to the bottom-up reduction of HSZ that lie at depth $>110 \mathrm{~m}$. 


\subsection{Comparison with previous work}

Previously Lamarque (2008) and Biastoch et al. (2011) considered the response of the hydrate inventory to the AR4 doubled $\mathrm{CO}_{2}$-conditions $\left(1 \%-\mathrm{CO}_{2}\right.$ increase $\left.\mathrm{yr}^{-1}\right)$ (hereafter $\left.2 \times C \mathrm{O}_{2}^{A R 4}\right)$. Comparison of $2 \times C \mathrm{O}_{2}^{A R 4}$ against the AR5 RCP multi-gas emission scenarios is difficult. If one considers $2100 \mathrm{CO}_{2}$-equivalents then $\mathrm{AR} 4$ doubled $\mathrm{CO}_{2}(\sim 735 \mathrm{ppm}$ $\mathrm{CO}_{2}$ ) should lie between RCP 4.5 ( $\sim 650$ ppm $\mathrm{CO}_{2}$-eq) and RCP 6.5 ( 850 ppm $\mathrm{CO}_{2}$-eq) (Van Vuuren et al., 2011).

Biastoch et al. (2011) modelled the change in HSZ extent over the entire Arctic Ocean. Assuming a hydrate fill fraction of 6.1 and $2.4 \%$ for $>70^{\circ} \mathrm{N}$ and 60 to $70^{\circ} \mathrm{N}$ respectively (based on ODP data and Lamarque (2008) ), they modelled rates of $\sim 146 \mathrm{Tg} \mathrm{CH}_{4}$ $\mathrm{yr}^{-1}$ (for $\mathrm{SRZ}=10 \mathrm{~m}$, Rüpke et al. (2011)). Our calculated RCP 4.5 - 6.0 mean Arctic dissociation rates under the same hydrate fill-fraction are 70 to 80 (250 max) $\mathrm{Tg} \mathrm{CH}_{4}$ $\mathrm{yr}^{-1}$, a range similar to Biastoch et al. (2011). For comparison, our maximum RCP 8.5 dissociation rate is $280 \mathrm{Tg} \mathrm{CH}_{4} \mathrm{yr}^{-1}$. Differences in modelling frameworks adopted by Biastoch et al. (2011) and used in this study would be expected to drive results which were different. For example Biastoch et al. (2011) use a potentially improved representation of bathymetry, applying a $2 \times 2^{\circ} 2 \times C O_{2}^{A R 4}$ anomaly to a $0.5 \times 0.5^{\circ}$ modern control state. Additionally, the use of different climate models (we use an ensemble of models, Biastoch et al. (2011) use a single model) and differences in thermal models (i.e. Biastoch et al. (2011) use $\chi$ of $4 \times 10^{-7} \mathrm{~m}^{2} \mathrm{~s}^{-1}$ ) and geothermal gradient maps would also be expected to generate dissimilar results. As would our use of a mask to specify the geographic envelope. Nevertheless, similarities in results suggest a level of robustness in the two methods.

Lamarque (2008) derived seafloor $\mathrm{CH}_{4}$ fluxes using paramerisations derived from the simulations of Reagan and Moridis $(2007,2008)$ along with a CMIP3 multi-model mean prediction of 2100 warming (regridded to $5 \times 5^{\circ}$ ). They derived an upper-estimate seafloor flux of 560 to $2140 \mathrm{Tg} \mathrm{CH}_{4} \mathrm{yr}^{-1}$ at 2100. At $1 \%$ hydrate pore-fill we obtained peak

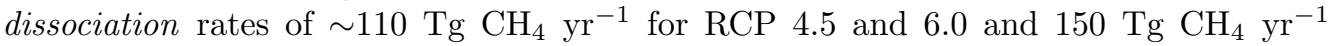
for RCP 8.5. Assuming average fill fractions (i.e. 1 to $3 \%$ ) our predictions remain significantly lower than Lamarque, if we assume $3 \%$ average fill-fraction we obtain 330 to $450 \mathrm{Tg} \mathrm{CH}_{4} \mathrm{yr}^{-1}$ (RCP 4.5 to 8.5 ) before considering the AOM sink. Lamarque interpolates from three distinct scenarios considered by Reagan and Moridis (2007), water depths of $1000 \mathrm{~m}\left(\mathrm{BWT}=4^{\circ} \mathrm{C}\right), 570 \mathrm{~m}\left(6^{\circ} \mathrm{C}\right)$ and $320 \mathrm{~m}\left(0.4^{\circ} \mathrm{C}\right)$ and $\triangle \mathrm{BWT}$ of $+1,3$ and $5^{\circ} \mathrm{C}$. Interpolation was carried out in terms of $\triangle \mathrm{BWT}$ and water depth disregarding initial BWT. The initial BWT determines if the HSZ is susceptible to shrinkage from the top-down, and so it's questionable if this method is capable of accurately capturing nearterm HSZ reduction. For example, despite large $\triangle B W T$, THSZ could remain in the water column. One would therefore expect this to contribute to Lamarque's overestimation of the global sea floor $\mathrm{CH}_{4}$ flux.

\section{Discussion}

We have used numerical models to study how the global Hydrate Stability Zone volume (gHSZv) and hydrate inventory will potentially respond to future climate and sea-level change. The results have demonstrated the sensitivity of the gHSZv and inventory during each RCP climate change scenario and what may be expected to occur in the long term, over the next millennia. 
Comparing results from the two models (fixed fill-fraction vs. 1D hydrate model) we found that near-term dissociation arising from top-down HSZ reduction is particularly sensitive to the vertical hydrate distribution. Hydrate forms in the HSZ when the local $\mathrm{CH}_{4}$ concentration exceeds $\mathrm{CH}_{4}$ solubility, with the former generally assumed to approach zero at the seafloor. Some (i.e. Reagan and Moridis (2007), Biastoch et al. (2011) ) assume hydrate saturation immediately beneath the the SRZ is equal-to or exceeds local solubility. Others (such as Rempel and Buffett (1998), Xu et al. (2001), Buffett and Archer (2004), Bhatnager et al. (2007), Marquardt et al. (2010) ) predict a gradual increase in hydrate saturation starting from a point well-below the SRZ and achieving maximum hydrate saturation at depth, i.e. deep-seated hydrates (Kvenvolden, 1988a). This could explain ambiguity in previous studies that considered the sensitivity of the hydrate inventory to climate change. Predictions of deep-seated hydrates often lead to assumptions of geological time-scale dissociation (i.e. shoaling of BHSZ). This discrepancy could originate from the balance between in-situ and migrating fluid methane sources (Rempel and Buffett, 1998). To improve on the 1D modelling of hydrate would require improved submodels of sedimentation and the accumulation of particulate organic carbon, microbial degradation of organic matter, inflow of methane-bearing fluids, porewater flow, methane solubility as well as sediment properties including inhomogeneities and geochemistry.

The pre-industrial inventory derived in this study was effectively tuned to the presentday, relying upon data which is calibrated to the modern organic carbon input (i.e. sedimentation rates, particulate organic carbon and dissolved oxygen). We also do not take into account the fraction of the margin which is believed to be underlain with hydrate. Borowski et al. (1999) considered the geographic distribution of sulphate-methane profiles and estimated that $\sim 30 \%$ of continental margins with HSZ would contain methane hydrate. Milkov (2004) considered the estimate of Borowski et al. (1999) to represent an upper limit and suggested $10 \%$ as the lower limit.

The step-nature of bathymetry imposed by the $2 \times 2^{\circ}$ spatial resolution in combination with the computational mask restricts the HSZ geometry that can be modelled. For example the lens-shaped HSZ cross section at continental margins may be inadequately modelled and so misrepresent the initial shoaling of the landward shallow-water deposits, a process supported by observations (Westbrook et al., 2009) and modelling (Dickens, 2001, Reagan and Moridis, 2009, Ruppel, 2011). Similarly coarse grids may inhibit the modelling of sensitive shelf-edge hydrates around the Arctic basin under influence of North Atlantic Intermediate Waters demonstrated by Biastoch et al. (2011). Unfortunately, the spatial resolution of many CMIP5 ocean models do not permit these fine-scale processes to be represented consistently.

The fate of $\mathrm{CH}_{4}$ following hydrate dissociation is complex. Increases in pore volume and/or pressure can drive vertical gas migration. Slower releases occur via advective transport in aqueous fluids or diffusion through sediments, processes where $\mathrm{CH}_{4}$ is more likely to be oxidised anaerobically by sedimentary microbial processes. Transport of $\mathrm{CH}_{4}$ from seafloor to atmosphere depends upon numerous factors including the $\mathrm{CH}_{4}$ seafloor flux rate, microbial oxidation rate, $\mathrm{CH}_{4}$-phase (i.e. dissolved or gaseous), water column $\mathrm{CH}_{4}$ saturation, water depth, and the extent of vertical mixing and upwelling (Mau et al., 2007, O'Connor et al., 2010, Valentine, 2011). Many of the biogeochemical processes are poorly constrained due to limited observations and interpretational difficulties. Within the high-flow rate regime of Hydrate Ridge between 50 and $100 \%$ of rising $\mathrm{CH}_{4}$ was 
oxidised by AOM (Treude et al., 2003). Using these estimates RCP 8.5 seafloor $\mathrm{CH}_{4}$ fluxes could peak at $\sim 75-140 \mathrm{Tg} \mathrm{CH}_{4} \mathrm{yr}^{-1}$ (first assuming $3 \%$ fill fraction and then the Arctic fill fraction of Biastoch et al. (2011)), exceeding the natural global flux estimated to be $30-50 \mathrm{Tg} \mathrm{CH}_{4} \mathrm{yr}^{-1}$ (Judd, 2003). Subsequent $\mathrm{CH}_{4}$ oxidation in the water column would lead to the regional expansion of sub-oxic waters, increase sea-water acidity and imbalance nutrient supplies. Using measurements from a large seepage zone, Mau et al. (2007) estimated that $1 \%$ of the diffusive $\mathrm{CH}_{4}$ seafloor flux reached the overlying atmosphere. Assuming a scenario in which $0.5 \%$ of dissociated hydrate $\mathrm{CH}_{4}$ reaches the atmosphere we estimate peak atmospheric RCP $8.5 \mathrm{CH}_{4}$ fluxes at 2100 to be $0.75-1.4$ $\mathrm{Tg} \mathrm{CH}_{4} \mathrm{yr}^{-1}$. Whilst substantial this is significantly lower than current $\sim 582 \mathrm{Tg} \mathrm{CH}_{4}$ $\mathrm{yr}^{-1}$ natural and anthropogenic $\mathrm{CH}_{4}$ surface emissions (Denman et al., 2007). It should be noted that these sea-floor and atmospheric $\mathrm{CH}_{4}$ fluxes are derived from site-specific estimates of sedimentary and water-column $\mathrm{CH}_{4}$ sinks, and do not capture the degree of spatial inhomogeneity which is likely to be present in such complex systems.

\section{Conclusions}

In the results presented we attempt to quantify effects of temperature and sea-level change on the future evolution of the global hydrate stability zone volume (gHSZv) and hydrate inventory. We force numerical models with RCP scenarios from the CMIP5 multi-model ensemble to specify changing bottom water temperatures along with linear models of sea-level change.

The evolution of gHSZv depends strongly upon $\mathrm{CO}_{2}$-eq forcing. Sea-level change effects becomes apparent in gHSZv-evolution from $\sim 2100$ onwards but even the large rates $\left(>15 \mathrm{~mm} \mathrm{yr}^{-1}\right)$ cannot significantly counteract thermal effects even for low $\mathrm{CO}_{2}$-eq forcing (i.e. RCP 4.5). From 2000 to 2300 gHSZv reduction primarily occurs in the Arctic and Subarctic beneath $<500 \mathrm{~m}$ water depth within the upper $100 \mathrm{~m}$ of sediment. Prior to 2100 lower-latitudes contribute little but intensify over the next two centuries, with dissociation occurring beneath deeper waters $(>500 \mathrm{~m})$.

Specifying hydrate-fill as a fixed-fraction of pore space, we find global dissociation rates due to RCP scenarios are indistinguishable prior to $\sim 2050$, attributable to cancelingeffects of RCP subset models and propagation timescales of water column warming. As with gHSZv, dissociation rates then diverge in response to $\mathrm{CO}_{2}$-eq forcing. Similarly it is difficult to ascertain the small effect of sea level change prior to $\sim 2100$. Over century timescales global dissociation rates are relatively insensitive to low rates of sea level change $\left(<\sim 10 \mathrm{~mm} \mathrm{yr}^{-1}\right)$ particulary for large $\mathrm{CO}_{2}$-eq forcings. Dissociation rates derived from the $1 \mathrm{D}$ hydrate model are significantly smaller than fixed-fraction estimates which we ascribe to the sensitivity of dissociation rates to the vertical distribution of hydrate within the sediment column. Future work will investigate hydrate model boundary conditions to provide more realistic hydrate distributions.

\section{Acknowledgements}

We would like to thank three anonymous reviewers for their excellent reviews as well as Jeff Ridley for invaluable insight into the CMIP5 experiment design. This work was conducted under NERC grant NE/J005290/1 and initial model development under 
NERC grant NE/I028610/1. SJH would like to thank Matthew Davie, Bruce Buffett and David Archer for providing the original 1D hydrate model, Martin Juckes and the British Atmospheric Data Centre (BADC) for data provision and organising the UK CMIP5 community. We acknowledge the World Climate Research Programme's Working Group on Coupled Modelling and thank the climate modeling groups (listed in Table 2) for producing and making available their model output. We also acknowledge the U.S. Department of Energy's Program for Climate Model Diagnosis and Intercomparison, as well as the Global Organization for Earth System Science Portals. DSG acknowledges financial support provided by the Grant of the President of the Russian Federation (MK6932.2012.1).

\section{References}

Archer, D., 2007. Methane hydrate stability and anthropogenic climate change. Biogeosciences 4 (4), 521-544.

Archer, D. E., Morford, J. L., Emerson, S. R., 2002. A model of suboxic sedimentary diagenesis suitable for automatic tuning and gridded global domains. Global Biogeochemical Cycles 16 (1), doi 10.1029/2000GB001288

Bhatnager, G., Chapman, W. G., Dickens, G. R., Dugan, B., Hirasaki, G. J., 2007. Generalisation of gas hydrate distribution and saturation of marine sediments by scaling of thermodynamic and transport processes. American Journal of Science 307, 861-900.

Biastoch, A., Treude, T., Rupke, L. H., Riebesell, U., Roth, C., Burwicz, E. B., Park, W., Latif, M., Boning, C. W., Madec, G., Wallmann, K., 2011. Rising arctic ocean temperatures cause gas hydrate destabilization and ocean acidification. Geophysical Research Letters 38 (L08602), doi:10.1029/2011GL0472222.

Borowski, W. S., Paull, C. K., Ussler, W., 1999. Global and local variations of interstitial sulfate gradients in deep-water, continental margin sediments: Sensitivity to underlying methane and gas hydrates. Marine Geology 159 (1-4), 131-154.

Boswell, R., Collett, T., 2010. Current perspectives on gas hydrate resources. Energy and Environmental Science 4, 1206-1215.

Buffett, B., Archer, D., 2004. Global inventory of methane clathrate: sensitivity to changes in the deep ocean. Earth and Planetary Science Letters 227 (3-4), 185-199.

Burwicz, E. B., Rüpke, L. H., Wallmann, K., 2011. Estimation of the global amount of submarine gas hydrates formed via microbial methane formation based on numerical reaction-transport modeling and a novel parameterizations of holocene sedimentation. Geochemica et Cosmochimica Acta 75, $4562-4576$.

Claypool, G. E., Kvenvolden, K. A., 1983. Methane and other hydrocarbon gases in marine sediment. Annual Review Earth and Planetary Science 11, 299-327.

Davie, M. K., 2002. Numerical models for the formation of marine gas hydrates: Constraints on methane supply from a comparison of observations and numerical models. Ph.D. thesis. Department of Earth and Ocean Sciences, The University of British Columbia.

Davie, M. K., Buffett, B. A., 2001. A numerical model for the formation of gas hydrate below the seafloor. Journal of Geophysical Research 106, 497-514.

Davie, M. K., Buffett, B. A., 2003. Sources of methane for marine gas hydrate: inferences from a comparison of observations and numerical models. Earth and Planetary Science Letters 206 (1-2), 51-63.

Davis, E. E., Hyndman, R. D., Villinger, H., 1990. Rates of fluid expulsion across the northern cascadia accretionary prism: Constraints from new heat row and multichannel seismic reflection data. Journal of Geophysical Research 95 (B6), 8869-8889.

Denman, K., Brasseur, G., Chidthaisong, A., Ciais, P., Cox, P. M., Dickinson, R. E., Hauglustaine, D., Heinze, C., Holland, E., Jacob, D., Lohmann, U., Ramachandran, S., da Silva Dias, P. L., Wofsy, S. C., Zhang, X., 2007. Couplings Between Changes in the Climate System and Biogeochemistry. In: Solomon, S., Qin, D., Manning, M., Chen, Z., Marquis, M., Averyt, K. B., Tignor, M., Miller, H. L. (Eds.), Climate Change 2007: The Physical Science Basis. Contribution of Working Group I to the Fourth Assessment Report of the Intergovernmental Panel on Climate Change. Cambridge University Press, Cambridge. 
D'Hondt, S., Rutherford, S., Spivack, A. J., 2002. Metabolic activity of subsurface life in deep-sea sediments. Science 295 (5562), 2067-2070.

Dickens, G. R., 2001. The potential volume of oceanic methane hydrates with variable external conditions. Organic Geochemistry 32 (10), 1179-1193.

Fyke, J. G., Weaver, A. J., 2006. The effect of potential future climate change on the marine methane hydrate stability zone. Journal of Climate 19 (22), 5903-5917.

Garcia, H. E., Locarnini, R. A., Boyer, T. P., Antonov, J. I., 2006. World ocean atlas 2005, volume 3: Dissolved oxygen, apparent oxyygen utilisation. In: Levitus, S. (Ed.), NOAA Atlas NESDIS 63. U.S. Governement Printing Office, Washington DC.

Golmshtok, A. Y., Soloviev, V. A., 2006. Some remarks on the thermal nature of the double BSR. Marine Geology 229 (3-4), 187-198.

Gornitz, V., Fung, I., 1994. Potential distribution of methane hydrates in the world's oceans. Global Biogeochemical Cycles 8.

Hamza, V. M., Cardoso, R. R., Ponte Neto, C. F., 2008. Spherical harmonic analysis of earth's conductive heat flow. International Journal of Earth Science (Geol Rundsch) 97, 205-226.

Harvey, L. D. D., Huang, Z., 1995. Evaluation of the potential impact of methane clathrate destabilization on future global warming. Journal of Geophysical Research 100 (D2), 2905-2926.

Jackett, D. R., McDougall, T. J., Feistel, R., Wright, D. G., Griffies, S. M., 2006. Algorithms for density, potential temperature, conservation temperature and freezing temperature of seawater. Journal of Atmospheric and Oceanic Technology 23, 1709-1728.

Jevrejeva, S., Moore, J. C., Grinstead, A., 2010. How will sea level respond to changes in natural and anthropogenic forcings by 2100? Geophysical Research Letters 37 (L07703, doi:10.1029/2010GL042947).

Jones, P. W., 2001. A User's Guide to SCRIP: A Spherical Coordinate Remapping and Interpolation Package (Version 1.4), Los Alamos National Laboratory, NM.

Judd, A. G., 2003. The global importance and context of methane escape from the seabed. Geo-Mar Letters 23, 147-154.

Klauda, J. B., Sandler, S. I., 2005. Global distribution of methane hydrate in ocean sediment. Energy and Fuels 19 (2), 459-470.

Kvenvolden, K. A., 1988a. Methane hydrate - a major reservoir of carbon in the shallow geosphere? Chemical Geology 71 (1-3), 41-51.

Kvenvolden, K. A., 1988b. Methane hydrates and global climate. Global Biogeochemical Cycles 2 (3), 221-229.

Kvenvolden, K. A., 1999. Potential effects of gas hydrate on human welfare. Proceedings of the National Academy of Sciences of the United States of America 96 (7), 3420-3426.

Lamarque, J.-F., 2008. Estimating the potential for methane clathrate instability in the $1 \%-\mathrm{CO}_{2} \mathrm{IPCC}$ AR-4 simulations. Geophysical Research Letters 35 (19), L19806.

Locarnini, R. A., Mishonov, A. V., Antonov, J. I., Boyer, T. P., Garcia, H. E., 2006. World ocean atlas 2005, volume 1: Temperature. In: Levitus, S. (Ed.), NOAA Atlas NESDIS 61. U.S. Government Printing Office, Washington, DC.

MacDonald, G. J., 1990. The future of methane as an energy resource. Annual Review of Energy 15 53-83

Marquardt, M., Hensen, C., Piñero, E., Wallmann, K., Haeckel, M., 2010. A transfer function for the prediction of gas hydrate inventories in marine sediments. Biogeosciences 7 (1), 2925-2941.

Mau, S., Valentine, D. L., Clark, J. F., Reed, J., Camilli, R., Washburn, L., 2007. Dissolved methane distribution and air-sea flux in the plume of a massive seep field, coal oil point, california. Geophysical Research Letters 34 (L22603), doi:10.1029/2007GL031344.

Meinshausen, M., Smith, S. J., Calvin, K., Daniel, J. S., Kainuma, M. L. T., Lamarque, J.-F., Matsumoto, K., Montzka, S. A., Raper, S. C. B., Riahi, K., Thomson, A., Velders, G. J. M., van Vuuren, D. P. P., 2011. The rcp greenhouse gas concentrations and their extensions from 1765 to 2300. Climatic Change DOI 10.1007/s10584-011-0156-z.

Middelburg, J. J., Soetaer, K., Herman, P. M. J., 1997. Empirical relationships for use in global diagenetic models. Deep-Sea Research I 44 (2), 327-344.

Milkov, A. V., 2004. Global estimates of hydrate-bound gas in marine sediments: how much is really out there? Earth-Science Reviews 66 (3-4), 183-197.

Milkov, A. V., Claypool, G. E., Lee, Y.-J., Xu, W., Dickens, G. R., Borowski, W. S., Party, O. L. . S., 2003. In situ methane concentrations at hydrate ridge, offshore oregon: New constraints on the global gas hydrate inventory from an active margin. Geological Society of America, 803-836.

Moss, R. H., Edmonds, J. A., Hibbard, K. A., Manning, M. R., Rose, S. K., van Vuuren, D. P., Carter, T. R., Emori, S., Kainuma, M., Kram, T., Meehl, G. A., Mitchell, J. F. B., Nakicenovic, J. P., Riahi, 
K., Smith, S. J., Stouffer, R. J., Thomson, A. M., Weyant, J. P., Wilbanks, T. J., 2010. The next generation of scenarios for climate change research and assessment. Nature 463, 747-756.

O’Connor, F., Boucher, O., Gedney, N., Jones, C. D., Folberth, G. A., Coppell, R., Friedlingstein, P. Collins, W. J., Chappellaz, J., Ridley, J., Johnson, C. E., 2010. Possible role of wetlands, permafrost, and methane hydrates in the methane cycle under future climate change: A review. Reviews of Geophysics 48, RG4005.

Piñero, E., Marquardt, M., Hensen, C., Haeckel, M., Wallmann, K., 2012. Estimation of the global inventory of methane hydrates in marine sediments using transfer functions. Biogeosciences Discussions $9,581-626$.

Pollack, H. N., Hurter, S. J., Johnson, J. R., 1993. Heat flow from the earth's interior: Analysis of the global data set. Reviews of Geophysics 31 (3), 267-280.

Rahmstorf, S., 2007. A semi-empirical approach to projecting future sea-level rise. Science 315, 368-370.

Reagan, M. T., Moridis, G. J., 2007. Oceanic gas hydrate instability and dissociation under climate change scenarios. Geophysical Research Letters 34, L22709, doi:10.1029/2007GL031671.

Reagan, M. T., Moridis, G. J., 2008. Dynamic response of oceanic hydrate deposits to ocean temperature change. Journal of Geophysical Research 113, C12023, doi:10.1029/2008JC004938.

Reagan, M. T., Moridis, G. J., 2009. Large-scale simulation of methane hydrate dissociation along the west spitsbergen margin. Geophysical Research Letters 36 (L23612).

Rempel, A. W., Buffett, B. A., 1998. Mathematical models of gas hydrate accumulation. Geological society of London, Special Publications 137, 63-74.

Rüpke, L., Biastoch, A., Treude, T., Riebesell, U., Roth, C., Burwicz, E., Park, W., Latif, M., Böning, C., Wallmann, K., Madec, G., 2011. Rising arctic ocean temperatures cause gas hydrate destabilization and ocean acidification. In: $7^{\text {th }}$ International Conference on Gas Hydrates (ICGH). Edinburgh, Scotland.

Ruppel, C., 2011. Methane hydrates and contempory climate change. Nature Education Knowledge $2(12)$.

Shapiro, N. M., Ritzwoller, M. H., 2004. Inferring surface heat flux distributions guided by a global seismic model: particular application to antarctica. Earth and Planetary Science Letters 223, 213224 .

Solomon, S., Qin, D., Manning, M., Chen, Z., Marquis, M., Averyt, K. B., Tignor, M., Miller, H. L., 2007. IPCC, 2007: Climate Change 2007: The Physical Science Basis. Contribution of Working Group I to the Fourth Assessment Report of the Intergovernemental Panel on Climate Change. Cambridge University Press, Cambridge.

Taylor, K. E., Stouffer, R. J., Meehl, G. A., 2011. A Summary of the CMIP5 Experiment Design. Bulletin of the American Meteorological Society 93, 485-498.

Tishchenko, P., Hensen, C., Wallmann, K., Wong, C. S., 2005. Calculation of the stability and solubility of methane hydrate in seawater. Chemical Geology 219 (1-4), 37-52.

Treude, T., Boetius, A., Knittel, K., Wallmann, K., Jørgensen, B. B., 2003. Anaerobic oxidation of methane above gas hydrates at Hydrate Ridge, NE Pacific Ocean. Marine Ecology Progress Series 264, 1-14.

U.S. Department of Commerce, National Oceanic and Atmospheric Administration, National Geophysical Data Centre 2006. 2-minute Gridded Global Relief Data (ETOPO2v2).

Valentine, D. L., 2011. Emerging topics in marine methane biogeochemistry. Annual Review of Marine Science 3, 147-171.

Van Vuuren, D. P., Edmonds, J., Kainuma, M., Riahi, K., Thomson, A., Hibbard, K. A., Hurtt, G. C., Kram, T., Krey, V., Lamarque, J.-F., Masui, T., Meinshausen, M., Nakicenovic, N., Smith, S. J., Rose, S. K., 2011. The representative concentration pathways: an overview. Climatic Change 109, 5-31.

Vermeer, M., Rahmstorf, S., 2009. Global sea level linked to global temperature. Proceedings of the National Academy of Sciences 106 (51), 21527-21532.

Wallmann, K., Burwicz, E., Ruepke, L., Marqardt, M., Piñero, E., Haeckel, M., Hensen, C., 2011. Constraining the global inventory to methane hydrate in marine sediments. In: 7 th International Conference on Gas Hydrates. Edinburgh, 17-21 July 2011.

Watterson, I. G., 1996. Non-dimensional measures of climate model performance. International Journal of Climatology 16, 379-391.

WCRP, 2012. CMIP5 coupled model intercomparison project, http://www.cmip-pcmdi.llnl.gov/ cmip5/

Westbrook, G. K., Thatcher, K. E., Rohling, E. J., Piotrowski, A. M., Pälike, H., Osborne, A. H., Nisbet, E. G., Minshull, T. A., Lanoisellé, M., James, R. H., Hühnerbach, V., Green, D., Fisher, 
R. E., Crocker, A. J., Chabert, A., Bolton, C., Beszczynska-Möller, A., Berndt, C., Aquilina, A., 2009. Escape of methane gas from the seabed along the West Spitsbergen continental margin. Geophysical Research Letters 36 (15), L15608.

Xu, W., Lowell, R. P., Peltzer, E. T., 2001. Effect of seafloor temperature and pressure variations on methane flux from a gas hydrate layer: Comparison between current and late Paleocene climate conditions. Journal of Geophysical Research 106 (B11), 26,413-26,423. 


\section{Table Captions}

Table 1. RCP overview. Overview of the Representative and Extended Concentration Pathway (RCP and ECP) scenarios. Descriptions derived from Moss et al. (2010), Van Vuuren et al. (2011). Note that ECP 6.0 was not available within the Coupled Model Intercomparison Project (CMIP5) archive (as of Jan 2012) and so is not represented within this work.

Table 2. GCM descriptions. Overview of the Coupled Model Intercomparison Project (CMIP5) Fifth Assessment Report (AR5) models. BCC = Beijing Climate Centre, China Meteorological Administration, CCCMA = Canadian Centre for Climate Modelling and Analysis, CNRM-CERFAC = Centre National de Recherches Meteorlogiques / Centre European de Recherche et Formation Avancees en Calcul Scientifique, CSIRO-QCCCE = Commonwealth Scientific and Industrial Research Organization in collaboration with Queensland Climate Change Centre of Excellence, NASA GISS = NASA Goddard Institute for Space Studies, MOHC = Met Office Hadley Centre, INM = Institute for Numerical Mathematics, IPSL = Institut Pierre-Simon Laplace, MIROC = Japan Agency for Marine-Earth Science and Technology, Atmosphere and Ocean Research Institute (The University of Tokyo) and National Institute for Environmental Studies, MRI = Meteorological Research Institute, and NCC = Norwegian Climate Centre. Model specific definitions: $\mathrm{BL}=$ Boundary Layer. The data was supplied as either a Regular cartesian or Tripolar grid. Vertical co-ordinates are either fixed thickness (z-coord) or isopycnal systems ( $\rho$-coord). The score indicates the performance metric, specified as the product of $\mathrm{R}_{m}^{2}, \mathrm{R}_{o}^{2}$ and AMS.

Table 3. RCP experiments run. Representative and Extended Concentration Pathway (RCP and ECP) scenarios run by each model of Table 2 uploaded to the Fifth Coupled Model Intercomparison Project archive (CMIP5) as of January 2012. Note that there were no models that contributed to the ECP 6.0 experiment.

Table 4. Hydrate model parameters. Geographically invariant parameters used within the $1 \mathrm{D}$ hydrate model 


\section{Figure Captions}

Fig. 1. Continental shelf margins. $2 \times 2^{\circ}$ mask defining the continental shelf margins adapted from Buffett and Archer (2004).

Fig. 2. Terminology. The vertical extent of the Hydrate Stability Zone (HSZ) is determined by the intersection of the curve representing local temperature-pressure conditions with the hydrate phase-boundary (i.e. the stability boundary). The uppermost intersection depends upon water depth and Bottom Water Temperature (BWT) and can fall within the (a) water column or (b) sediment. If it is within the water column we equate the Top of the HSZ (THSZ) to the base of the Sulphate Reduction Zone (SRZ). Bottom of the Hydrate Stability Zone is denoted as BHSZ.

Fig. 3. Reduction in gHSZv. Reduction in the global Hydrate Stability Zone volume (gHSZv) due to each Representative Concentration Pathway (RCP) scenario without sea-level model.

Fig. 4. HSZ-loss distribution. Distribution of the global Hydrate Stability Zone volume (gHSZv) reduction in terms of overlying water depth (top) and sediment depth (bottom) for each scenario under fixed sea level. Discontinuity between corresponding RCP and ECP scenario due to different model subsets contributing to the multi-model mean. RCP scenarios have more contributing climate models and so provides greatest fidelity for predictions to 2100 (Table 3). Units are in $\mathrm{km}^{3}$ of HSZ decade ${ }^{-1}$.

Fig. 5. Business-as-usual HSZ-loss Latitudinal distribution. Multi-Model mean volumetric Hydrate Stability Zone (HSZ) loss $\left(\mathrm{km}^{3}\right)$ as a function of latitude for a range of water depths (D) between 2000-2100 under the RCP 8.5 business-as-usual scenario.

Fig. 6. Rates of hydrate dissociation. Multi-model mean average rates of hydrate dissociation for a globally-averaged hydrate saturation of $1 \%$ pore-space under varying sea-level models. Shaded region indicates prediction beyond RCP/ECP time frame (2100/2300) and so corresponds to fixed bottom water temperature (but changing sea-level). Note change from 10 to 50 year temporal resolution at year 2350 . (RCP/ECP $=$ Representative and Extended Concentration Pathway)

Fig. 7. Modelled rates of hydrate dissociation. Multi-model mean average rates of hydrate dissociation for Representative and Extended Concentration Pathway (RCP) scenarios derived from the 1D hydrate model. Note change from 10 to 50 year temporal resolution at year 2350 . 
Table 1:

\begin{tabular}{cl}
\hline Scenarios & Description \\
\hline RCP 4.5 & $\sim 4.5 \mathrm{~W} \mathrm{~m}^{-2}\left(\sim 650 \mathrm{ppm} \mathrm{CO}_{2}\right.$ equiv) at stabilization post-2100 (medium stabilization sce- \\
& nario) \\
RCP 6.0 & $\sim 6 \mathrm{~W} \mathrm{~m}^{-2}\left(\sim 850 \mathrm{ppm} \mathrm{CO}_{2}\right.$ equiv) at stabilization post-2100 (medium stabilization scenario) \\
RCP 8.5 & $\sim 8.5 \mathrm{~W} \mathrm{~m}^{-2}\left(\sim 1370 \mathrm{ppm} \mathrm{CO}_{2}\right.$ equiv) at 2100 (high-baseline emission scenario) \\
ECP 4.5 & Smooth transition from $2100-2150$ then emissions fixed. Stabilization at $4.5 \mathrm{~W} \mathrm{~m}^{-2}$ \\
ECP 6.0 & Smooth transition from $2100-2150$ then emissions fixed. Stabilization at $6 \mathrm{~W} \mathrm{~m}^{-2}$ \\
ECP 8.5 & Constant emissions $2100-2150$ with smooth transition to 2250. Concentrations fixed post- \\
& 2250. Stabilization at $12 \mathrm{~W} \mathrm{~m}^{-2}$ \\
\hline
\end{tabular}

Table 2:

\begin{tabular}{|c|c|c|c|c|c|}
\hline id & Name & Institute ID & $\begin{array}{l}\text { Model origin, type and grid specifica- } \\
\text { tion }\end{array}$ & $\begin{array}{l}\text { pre- } \\
\text { industrial } \\
\text { (years) }\end{array}$ & score \\
\hline 1 & BCC-CSM1.1 & $\mathrm{BCC}$ & MOM Tripolar $360 \times 300 z$-coord & 500 & 0 \\
\hline 2 & CanESM2 & CCCMA & MOM1 Regular $256 \times 192 z$-coord & 996 & 0.240 \\
\hline 3 & CNRM-CM5 & $\begin{array}{l}\text { CNRM- } \\
\text { CERFACS }\end{array}$ & $\begin{array}{l}\text { NEMO3.2 ORCA- } 1 \text { Tripolar } z \text {-coord } \\
362 \times 292 \text { partial-step BL }\end{array}$ & 850 & 0.555 \\
\hline 4 & CSIRO-Mk3.6.0 & $\begin{array}{l}\text { CSIRO- } \\
\text { QCCCE }\end{array}$ & MOM2.2 Regular $192 \times 192 z$-coord & 490 & 0.392 \\
\hline 5 & GISS-E2-R & NASA GISS & MOM3 Regular $288 \times 180 z$-coord & 1200 & 0.470 \\
\hline 6 & HadGEM2-ES & $\mathrm{MOHC}$ & $\begin{array}{l}\text { Bryan-Cox-Semtner Regular } 360 \times 216 \\
z \text {-coord }\end{array}$ & 240 & 0.514 \\
\hline 7 & INM-CM4 & INM & Regular $_{\text {modified }} 360 \times 340 \sigma$-coord & 500 & 0.369 \\
\hline 8 & IPSL-CM5A-LR & IPSL & $\begin{array}{l}\text { NEMO Tripolar } 182 \times 149 \quad z \text {-coord } \\
\text { partial-step }\end{array}$ & 1000 & 0.422 \\
\hline 9 & MIROC-ESM & MIROC & $\begin{array}{l}\text { Regular } 256 \times 1928-\sigma 41-z \text { and regional } \\
\text { BBL parameterisation }\end{array}$ & 531 & 0.270 \\
\hline 10 & MRI-CGCM3 & MRI & TriPolar $360 \times 368$ surf $\sigma+z$-coord & 500 & 0.466 \\
\hline 11 & NORESM1-M & NCC & MICOM Tripolar $320 \times 384 \rho$-coord & 501 & 0.301 \\
\hline
\end{tabular}

Table 3:

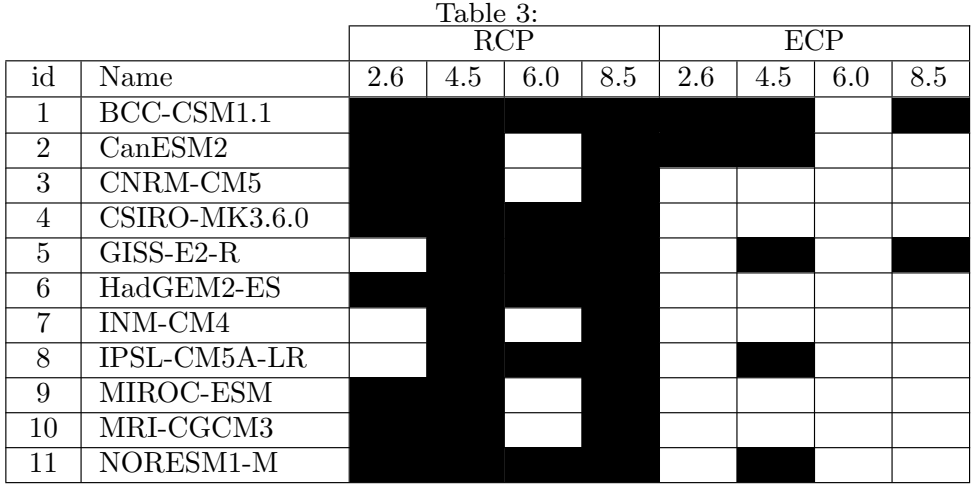




\begin{tabular}{ll}
\multicolumn{2}{c}{ Table 4: } \\
\hline Parameter & Value \\
\hline Porosity Depth Scale $(\mathrm{m})$ & 1500 \\
Seafloor Porosity & 0.65 \\
Sediment Thermal Conductivity $\left(\mathrm{Wm}^{-1} \mathrm{~K}^{-1}\right)$ & 1.5 \\
Sediment Thermal Diffusivity $\left(\mathrm{m}^{2} \mathrm{~s}^{-1}\right)$ & $5 \times 10^{-7}$ \\
Methanogenesis rate $\left(\mathrm{s}^{-1}\right)$ & $5 \times 10^{-15}$ \\
External Fluid Velocity $\left(\mathrm{mm} \mathrm{yr}^{-1}\right)$ & 0.3 \\
Sediment Density $\left(\mathrm{kg} \mathrm{m}^{-3}\right)$ & 2650 \\
Hydrate Density $\left(\mathrm{kg} \mathrm{m}^{-3}\right)$ & 930 \\
\hline
\end{tabular}

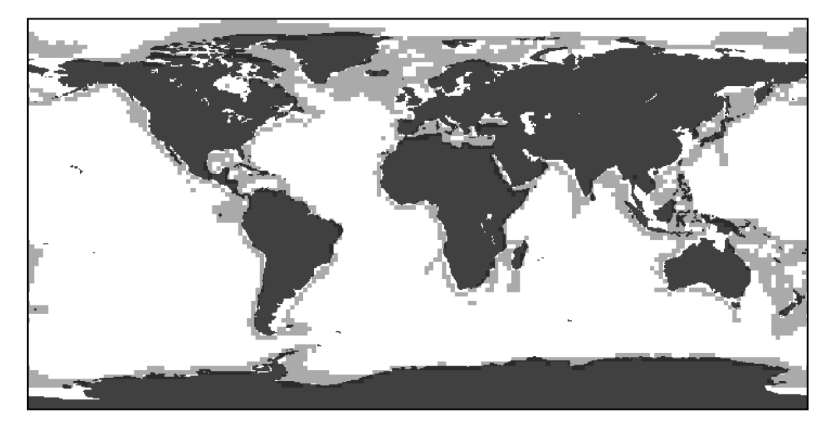

Figure 1: 


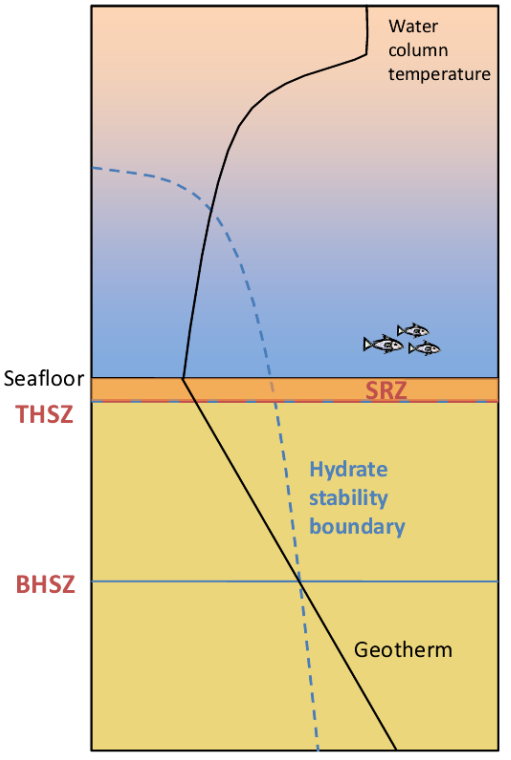

(a) $\mathrm{T}_{3}(\mathrm{P})$ water-sediment

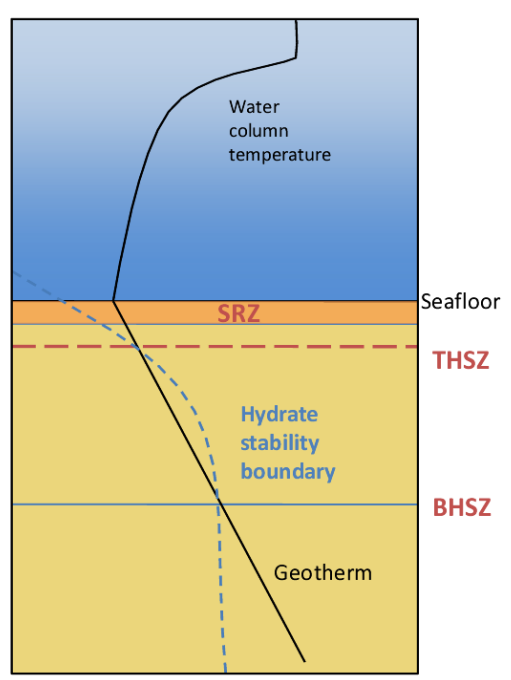

(b) $\mathrm{T}_{3}(\mathrm{P})$ sediment-sediment

Figure 2:

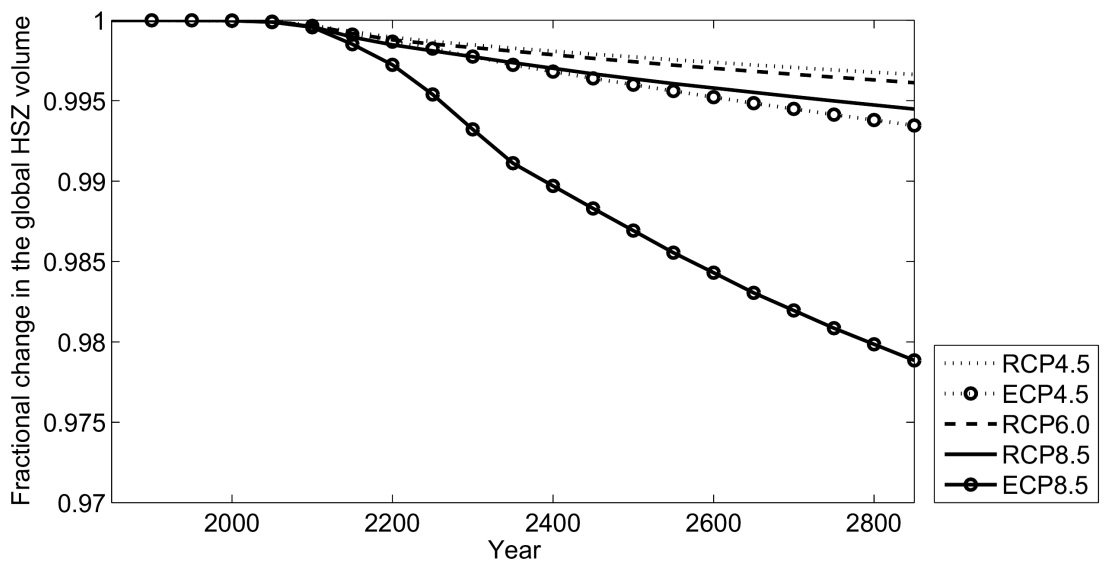

Figure 3: 

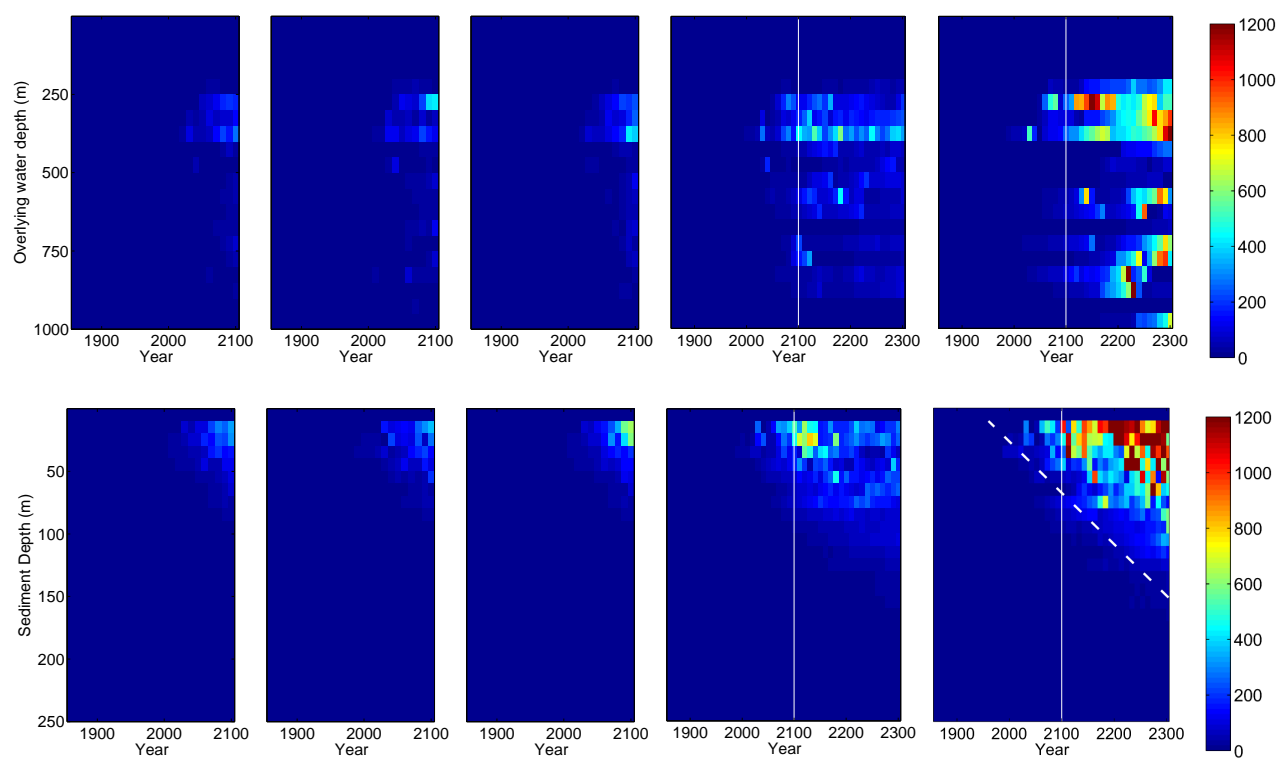

(a) $\mathrm{RCP} 4.5$

(b) RCP6.0

(c) $\mathrm{RCP} 8.5$

(d) ECP4.5

(e) ECP 8.5

Figure 4:

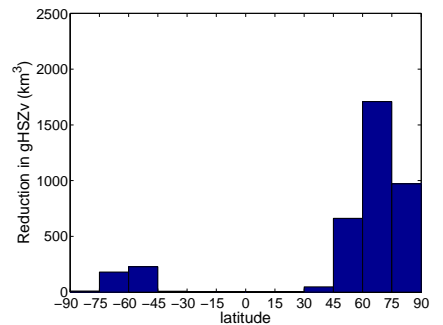

(a) $\mathrm{D}=<500 \mathrm{~m}$

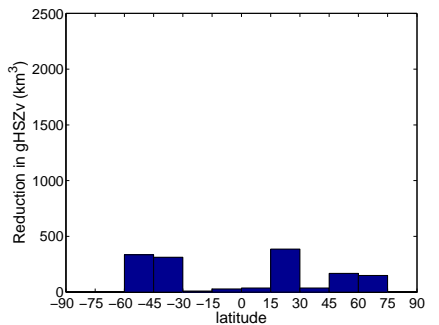

(b) $\mathrm{D}=500-1000 \mathrm{~m}$

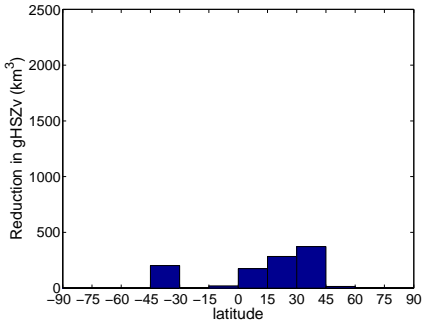

(c) $\mathrm{D}=>1000 \mathrm{~m}$

Figure 5: 


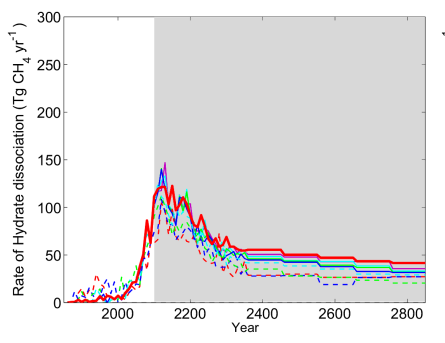

(a) RCP 4.5

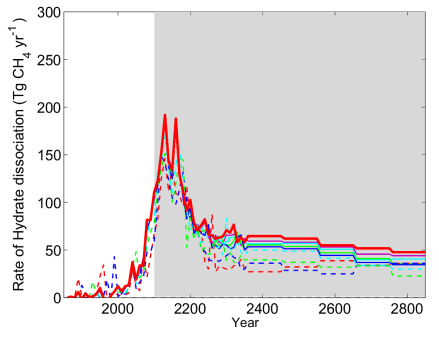

(b) RCP 6.0

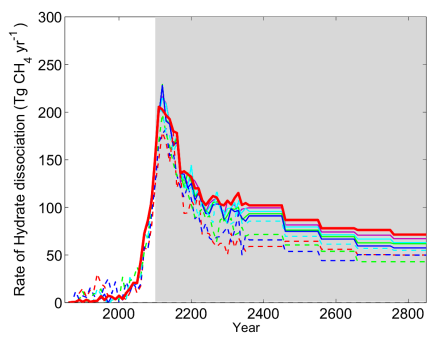

(c) RCP 8.5

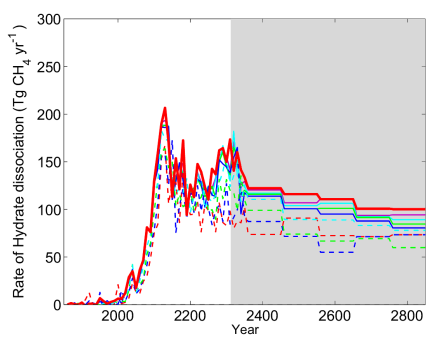

(d) $\mathrm{ECP} 4.5$

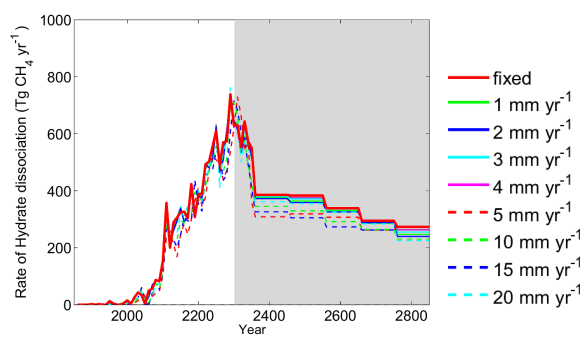

(e) ECP 8.5

Figure 6:

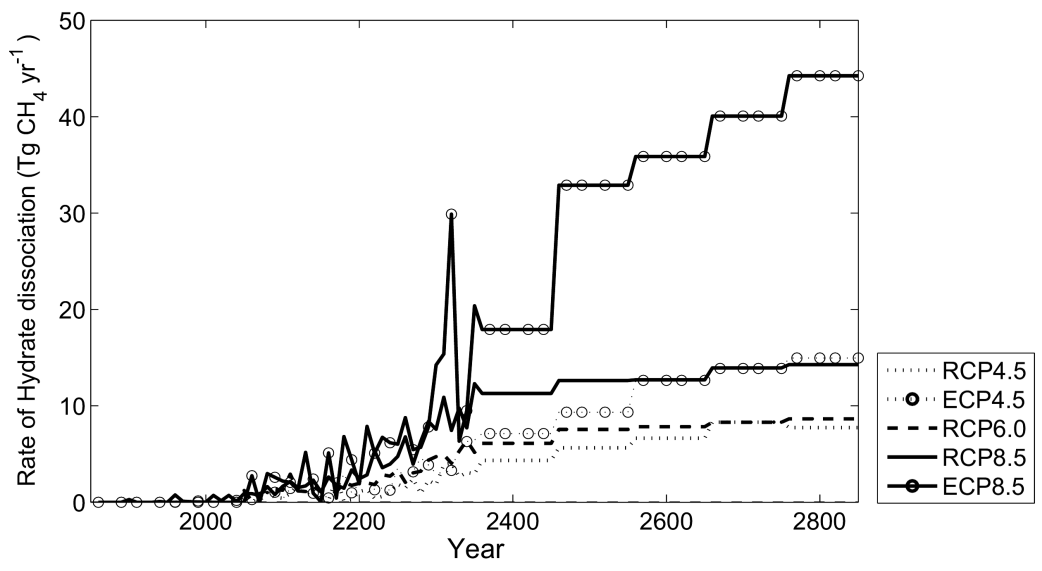

Figure 7: 